\title{
Endoscopic retrograde cholangiography with contrast ultrasonography
}

A 64-year-old woman with a body mass index of 50 was admitted to our intensive care unit with the clinical appearance of severe biliary pancreatitis. Bedside ultrasonography was difficult due to the patient's obesity but revealed a dilated common bile duct ( $\bullet$ Fig. 1). Conventional endoscopic retrograde cholangiography (ERC) with X-rays was considered impossible due to the obesity. Bedside endosonography (EG 3830UT; Pentax, Tokyo, Japan) was performed. Endoscopically a swollen papilla excreting pus was seen. Sonographically, large areas of fluid were demonstrated around the pancreatic body and tail. A small remainder of undamaged pancreatic tissue was seen in the pancreatic head. The gallbladder was large and full of small stones. The main hepatic duct was dilated and filled with stone material. Bedside ERC with a duodenoscope (TJF 160; Olympus, Tokyo, Japan) was performed using contrast ultrasonography instead of X-radiography. After cannulation of the common bile duct a second-generation ultrasound contrast agent (Sonovue) was injected through the papillotome. Bedside ultrasonography (Sequoia, Siemens) demonstrated the contrast agent in the common bile duct and in the right and left hepatic duct ( $\odot$ Fig. 2). After papillotomy, stones were extracted with a basket and a balloon.

Therapeutic ERC using X-rays poses a problem not only in obese patients but also in pregnant women, since fluoroscopy is a risk for the fetus. Traditionally the problem was solved by wire-guided cannulation by an experienced endoscopist using as little radiation as possible [13]. In slim patients ultrasonography without contrast agents may be helpful [4]. Contrast ultrasonography may combine the advantages of cholangiography with $\mathrm{X}$-rays and ultrasonography and should be further explored in this field.

Endoscopy_UCTN_Code_TTT_1AR_2AB

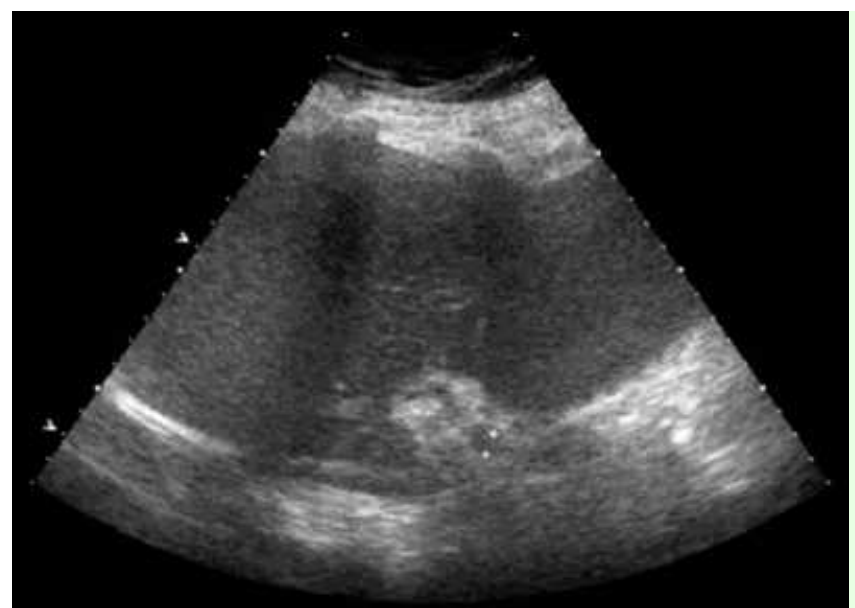

Fig. 1 Low-quality ultrasonography in an obese patient demonstrating a dilated common bile duct.
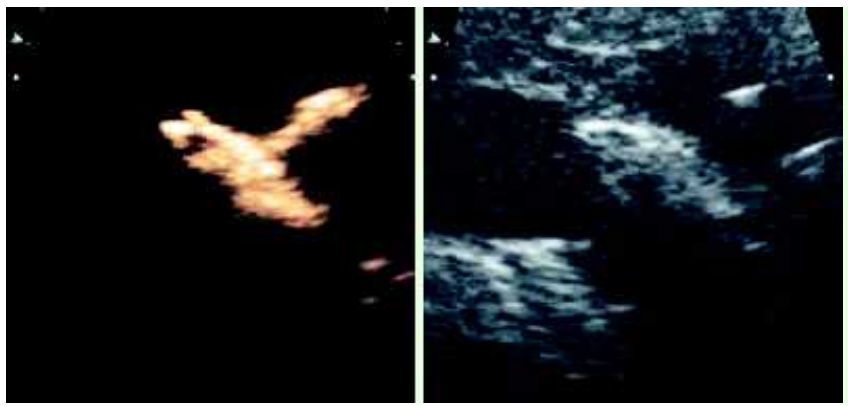

Fig. 2 Common hepatic duct with right and left branch visualized by bedside ultrasonography after the injection of ultrasound contrast agent through the papillotome.

\section{Zuber-Jerger, E. Endlicher,}

\section{J. Schölmerich, F. Klebl}

Department of Internal Medicine I, University of Regensburg, Regensburg, Germany

\section{References}

1 Kahaleh M, Hartwell GD, Arseneau KO et al. Safety and efficacy of ERCP in pregnancy. Gastrointest Endosc 2004; 60: 287-292

2 Duseja A, Jain P, Reddy CS et al. Safety and efficacy of ERCP in pregnancy. Gastrointest Endosc 2005; 61: $352-353$

3 Shelton J, Linder JD, Rivera-Alsina ME, Tarnasky PR. Commitment, confirmation, and clearance: new techniques for nonradiation ERCP during pregnancy. Gastrointest Endosc 2008; 67: 364-368

4 Pasquale L, Caserta L, Rispo A et al. Endoscopic management of symptomatic choledocholithiasis in pregnancy without the use of radiations. Eur Rev Med Pharmacol Sci 2007; 11: 343-346
Bibliography

DOI $10.1055 / \mathrm{s}-2008-1077434$

Endoscopy 2008; 40: E202

(C) Georg Thieme Verlag KG Stuttgart · New York ISSN 0013-726X

\section{Corresponding author}

\section{Zuber-Jerger, MD}

Department of Internal Medicine I

University of Regensburg

93042 Regensburg

Germany

Fax: +49-941-944-7073

ina.zuber-jerger@klinik.uni-regensburg.de 